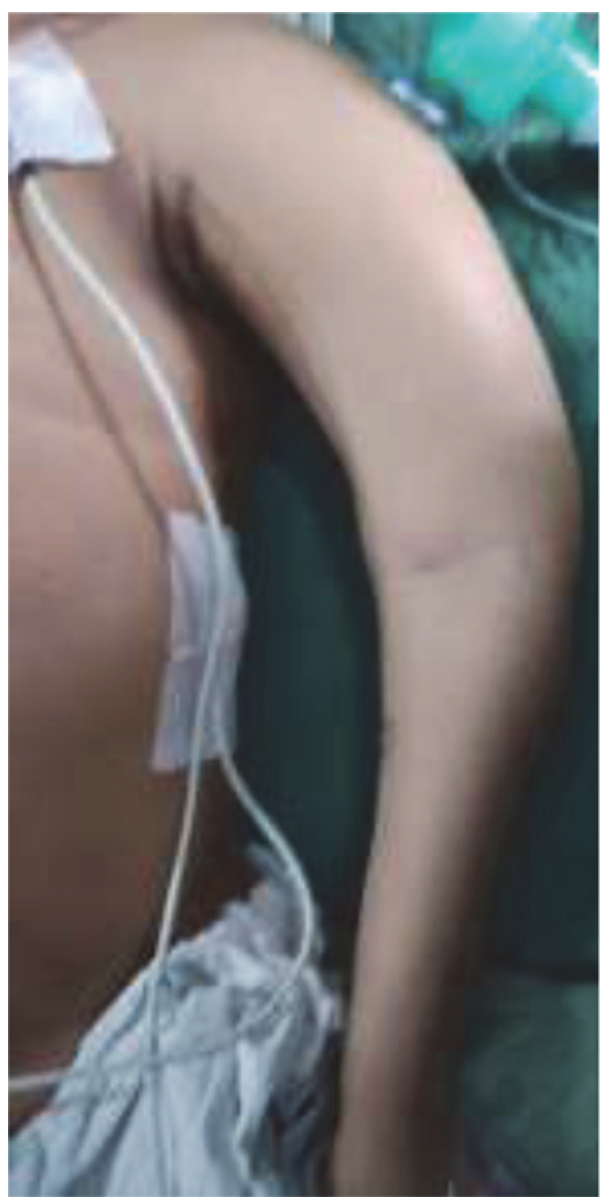

Abstract 26 Figure 2

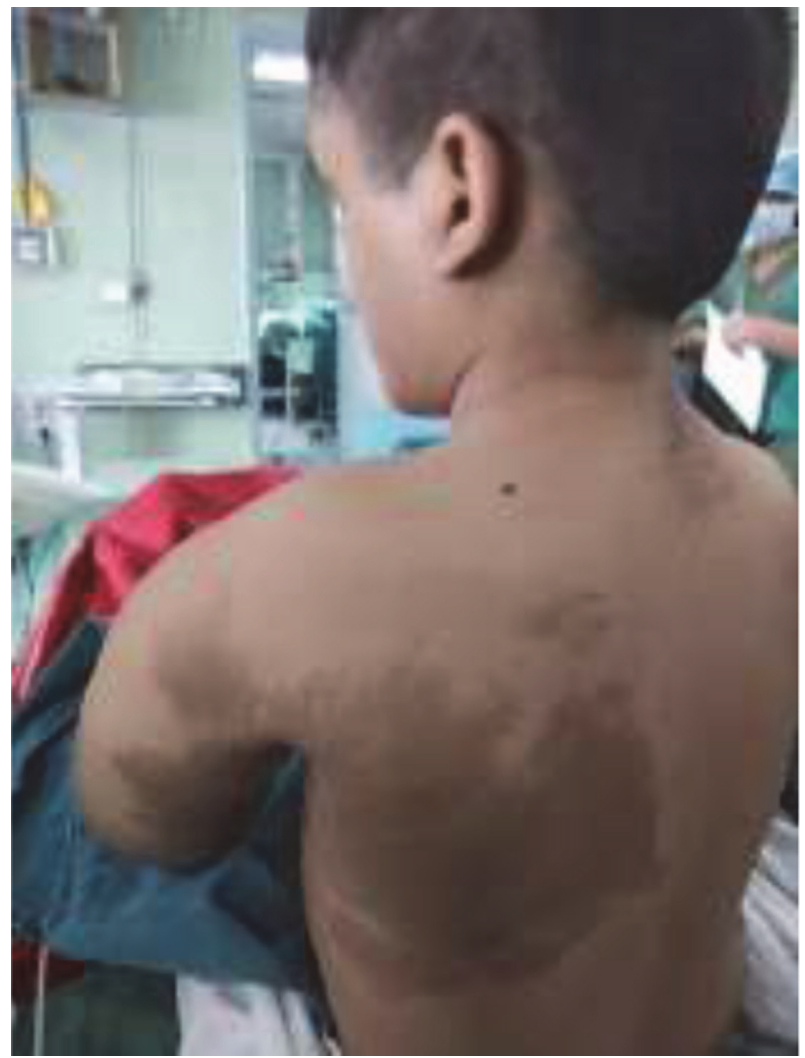

Abstract 26 Figure 3

\section{ANAESTHETIC MANAGEMENT IN PARTURIENT WITH COARCTATION OF AORTA, PATENT DUCTUS ARTERIOSUS AND ARNOLD CHIARI MALFORMATION FOR ELECTIVE CAESAREAN SECTION}

L Aishwarya*, RS Mane, MC Patil. Jawaharlal Nehru Medical College, KLE University, Belagavi, India

\subsection{6/rapm-2021-ESRA.27}

Background and Aims Coarctation of aorta represents 6\%-8\% of CHD with associated Patent ductus arteriosus. Arnold chiari malformation is characterized by prolapse of cerebellar tonsils below the foramen magnum causing compressive symptoms. The primary goal is to minimize the incidence of haemodynamic stressor response and brainstem herniation which is a possible risk with endotracheal intubation.

Methods A case of 24year G2P1L0 with 34weeks POG, a known case of ACM was diagnosed with COA and PDA. She was planned for elective caesarean due to uncontrolled upper limb hypertension. Examination revealed pansystolic murmur and Loud P2 with suzzman's sign positive. She had feeble femoral pulse with radiofemoral delay. Uppler limb BP : 190/ 100 mmhg and lowerlimb BP: 130/80 mmhg. 2DEcho revealed Large PDA with left to right shunt, dilated RA, RV. Severe COA with PPG 76 mmh. Trivial TR with PPG 40 mmhg. No sensory and motor deficits noted. Graded epidural anaesthesia was administered.

Results Parturient with congenital anomalies has been successfully managed perioperatively with graded epidural doses and by providing adequate post-operative analgesia.

Conclusions Parturient with Coarctation of the aorta and Arnold chiari malformation presents with unique challenges to the anaesthetist and management must be tailored to avoid hemodynamic instability and associated risk of tonsillar herniation. The use of epidural anaesthesia in graded dose was successful in achieving this goal.

\section{LOCAL ANAESTHETIC SYSTEMIC TOXICITY AFTER AXILLARY BRACHIAL PLEXUS BLOCK IN AMBULATORY SURGERY - A CASE REPORT}

${ }^{1} \mathrm{GS}$ Sousa*, ${ }^{2} \mathrm{M}$ Oliveira, ${ }^{2} \mathrm{P}$ Esperança, ${ }^{3} \mathrm{E}$ Segura Grau. ${ }^{1} \mathrm{C}$ entro Hospitalar Tondela-Viseu, Viseu, Portugal; ${ }^{2}$ Centro Hospitalar Universitário São João, Porto, Portugal; ${ }^{3}$ Anesthesiology, Centro Hospitalar Tondela-Viseu, Viseu, Portugal

\subsection{6/rapm-2021-ESRA.28}

Background and Aims Local anaesthetic systemic toxicity (LAST) is a rare but potentially fatal complication of regional anaesthesia. LAST affects two major systems, namely neurologic and cardiovascular ${ }^{1}$. The number of regional anaesthesia has been increasing and the risk of LAST, despite all the good practices, increases proportionally. Axillary brachial plexus block is reported as the most associated block to LAST events. $^{2}$

We pretend to increase awareness to this rare but lifethreatening entity.

Methods Case report and literature review.

Results A 55-years-old female patient, ASA II, was admitted for left hand ambulatory surgery. It was performed an ultrasound-guided axillary brachial plexus block. The left axillary artery and the branches of median, radial and cubital nerves were identified. Then $200 \mathrm{mg}$ of mepivacaine and $37.5 \mathrm{mg}$ of levobupivacaine were administered through an in-plane 